\title{
LIBERDADE DE REUNIÃO E DE MANIFESTAÇÃO NO ESTADO DE DIREITO ${ }^{1}$
}

\author{
RIGHT TO ASSOCIATION AND FREE SPEECH \\ IN THE STATE OF LAW
}

\author{
ANTÓNIO FRANCISCO DE SOUSA²
}

\begin{abstract}
RESUMO: O presente artigo trata do direito fundamental à liberdade de reunião e de manifestação no direito português. É apresentado um conceito e delineado o panorama dos limites e restrições a esse direito, mormente na atuação do Estado como poder de polícia. Conclui-se que a atuação das forças policiais encarregadas de salvaguardar a ordem e a segurança públicas deve ser clara e transparente, para que as restrições sejam legais e reduzidas ao mínimo indispensável.

PALAVRAS-CHAVE: Liberdade de Expressão; Direito de Reunião; Direitos Fundamentais; Limites e Restrições; Direito Português; Polícia.
\end{abstract}

ABSTRACT: This article addresses the fundamental right to association and free speech in Portuguese law. It introduces the concept of such rights and outlines their system of limits and restrictions, especially vis-à-vis de State's police power. The conclusion is that when acting to ensure order and public safety the State must do so in a clear and transparent fashion, in order for the restraints on these rights to be legal and limited to the bare minimum.

KEYWORDS: Free Speech; Right to Association; Fundamental Rights; Limits and Restrictions; Portuguese Law; Police.

SUMÁRIO: 1. Precisão Conceptual; 2. Enquadramento Geral; 3. Para o Conceito de Reunião; 4. Carácter Pacífico e sem Armas; 5. Reuniões Públicas e não Públicas; 6. Alcance da Garantia do Direito de Reunião; 7. Ingerências no Direito de Reunião; 8. Limitações à Liberdade de Reunião e de Manifestação; 9. Proibição de Exigências Injustificadas; 10. Proibição de Sujeição a Autorização; Conclusões; Bibliografia.

SUMMARY: 1. Conceptual Precision; 2. General Framing; 3. On the Concept of Association; 4. Pacific and Unarmed Character; 5. Public and non-public Association; 6. The Extent of the Right of Association Guarantee; 7. Restrictions on the Right to Association; 8. Restrictions on Free Speech and the Right to Association; 9. Prohibition of Unjustified Requirements; 10. Prohibition of Requiring prior Authorization; Conclusions; Bibliography.

Artigo recebido em 24.10.2012. Artigo aceito para publicação em 19.11.2012 mediante convite.

${ }^{1} \mathrm{O}$ presente texto corresponde, com poucas alterações, à comunicação por nós apresentada na PUCRS, no dia 25 de setembro de 2012.

${ }^{2}$ Professor da Faculdade de Direito da Universidade do Porto. Doutor pelas Faculdades de Direito e de Letras da Universidade do Porto. 
O tema da liberdade de reunião e de manifestação é, sem dúvida, um dos temas centrais do Estado de direito democrático, pois é através do exercício desta liberdade que os cidadãos podem exprimir livremente a sua opinião, criticar o poder, fazer exigências, enfim, erguer a voz contra a injustiça e a opressão. Sem liberdade de reunião e de manifestação não há verdadeira democracia: diz-me que liberdade de reunião e de manifestação praticas no teu país e dir-te-ei que democracia alcançaste.

Nesta curta reflexão sobre a liberdade de reunião e de manifestação são abordados alguns aspetos da vasta problemática que o tema suscita, que em geral tem sido por nós já tratada noutras oportunidades ${ }^{3}$.

\section{PRECISÃO CONCEPTUAL}

Diferentemente do que acontece com outras Constituições europeias, a Constituição da República Portuguesa (CRP) assume uma posição clara quanto a uma questão fundamental frequentemente discutida na doutrina: a de saber se o direito de reunião compreende o direito de manifestação ou se são dois direitos distintos. A epígrafe do art. $45^{\circ}$ da Constituição da República Portuguesa (CRP), seguida da estruturação clara do preceito em duas regulações distintas, não deixa dúvidas no sentido de que se trata de dois direitos distintos: "direito de reunião e de manifestação".

\section{ENQUADRAMENTO GERAL}

A liberdade de reunião e de manifestação é um "direito, liberdade e garantia" (Título II, Cap. 1 da CRP) de carácter "pessoal" (direito de "se reunir" - art. $45^{\circ}, \mathrm{n}^{\circ} 1$, da CRP) que assegura uma forma específica de comunicação do cidadão com os demais cidadãos. Trata-se, pois, de um direito fundamental de comunicação (bem evidente no "direito de manifestação"). A liberdade de reunião garantida no art. $45^{\circ}, n^{\circ} 1$, da CRP, abarca as reuniões em lugares públicos e/ou abertos ao público. Já a liberdade de manifestação pressupõe, por natureza, o contacto (a comunicação) com o público em geral, pelo que os seus lugares próprios de realização são os lugares públicos. A reserva de lei qualificada, constante do art. $45^{\circ}, n^{\circ} 1$, da CRP, para as reuniões públicas e/ou em lugares abertos ao público é reveladora de que para as reuniões em espaços fechados a garantia constitucional é sem reservas.

\section{PARA O CONCEITO DE REUNIÃO}

Antes de mais, a figura jurídico-constitucional da "reunião" não se confunde com os meros ajuntamentos e aglomerações de pessoas, por razões fortuitas ou, por exemplo, para assistir a um espectáculo. Para haver reunião em sentido jurídico-constitucional não é suficiente o simples encontro de várias pessoas. Este é sem dúvida indispensável, mas, para além dele, tem de haver a realização de um fim comum, que assegura uma ligação interna entre os presentes. Podemos dizer que os que assistem a um espetáculo,

\footnotetext{
${ }^{3}$ Cf. espec. Reuniões e Manifestações no Estado de Direito. 2. ed., São Paulo: Saraiva, 2011.
} 
por exemplo, os "curiosos" numa situação de acidente, prosseguem o mesmo fim, mas não um fim comum. É o fim comum presente no "reunir-se" (ou "manifestar-se") que assegura uma relação interna entre as pessoas presentes. Enquanto no simples ajuntamento ou aglomeração de pessoas os presentes prosseguem um fim próprio, sem necessitarem uns dos outros, já na reunião (ou manifestação), ainda que se trate de um direito pessoal, o seu exercício é colectivo. As pessoas presentes precisam umas das outras para exercerem o seu direito e prosseguirem o fim colectivo. Isto não impede, contudo, que os meros ajuntamentos se possam, mais ou menos espontaneamente, transformar em reuniões. Para tal, basta que no simples ajuntamento surja a qualquer momento a necessária ligação interna.

A exigência de um fim comum entre os presentes na reunião suscita algumas questões nem sempre fáceis de resolver. Uma delas assenta na distinção entre a formação e a manifestação da opinião, importando saber se o fim comum tem de existir nas duas, ou se pode verificar-se apenas em relação a uma delas. Por outro lado, o facto de se tratar de reuniões em lugares públicos ou abertos ao público (reuniões públicas, isto é, acessíveis a qualquer pessoa) coloca a questão de saber se o assunto objecto de reunião tem de ser, também ele, público, ou se pode ser discutido qualquer tipo de assunto. Trata-se sem dúvida de questões controversas, que têm tido adeptos em diferentes sentidos. Sem querer tomar posição definitiva sobre o assunto, parece-nos, no entanto, importante destacar aqui a extrema importância do carácter complementar que a liberdade de reunião mantém com a liberdade de opinião (na formação e manifestação da opinião). Por outro lado, da extrema importância que o direito de reunião (e de manifestação) ostenta no Estado de direito, será certamente de partir da liberdade como regra ou princípio geral e da proibição apenas como excepção confinada à reserva de lei ${ }^{4}$. Assim, são sem dúvida reuniões no sentido do art. $45^{\circ}$ da CRP, antes de mais, as concentrações de pessoas que têm por fim e por objeto o debate de ideias de carácter político. Este é, aliás, por excelência, historicamente, o domínio privilegiado das reuniões (e manifestações) públicas. Mas, embora o carácter de reunião possa ser questionável quando se trate de congressos meramente científicos ou de reuniões empresariais, parece-nos que ele também não pode ser, pura e simplesmente, restringido aos assuntos públicos. Uma tal restrição não respeitaria a letra e a posição sistemática do art. $45^{\circ}$ da CRP. O facto de, vistas as coisas historicamente, a luta pela liberdade de reunião se ter desencadeado predominantemente por causa

\footnotetext{
${ }^{4}$ Aderindo claramente a um conceito amplo de reunião, o Tribunal Constitucional Federal alemão considerou ( $E$ 69, 315/343) que estavam "protegidas as reuniões e os desfiles ... como expressão de desenvolvimento comunitário, tendo em vista a comunicação. Esta protecção não está limitada aos eventos em que se argumenta e discute, mas abarca formas diversificadas da conduta comum, incluindo as formas de expressão não verbal". Porém, já mais recentemente o mesmo Tribunal $(E 104,92 / 104)$ aderiu a um conceito bem mais restritivo de reunião ao limitar o fim da reunião à participação na formação de opinião pública.
} 
de concentrações políticas, não exclui que consideremos outros encontros igualmente dignos de protecção. Por conseguinte, a interpretação correcta do art. $45^{\circ}$ da CRP quanto ao objecto e ao fim da reunião (ou manifestação) não pode ser restrita, mas ampla, tão ampla quanto possível. Isto também resulta, para além do assinalado significado do direito de reunião (e de manifestação) no Estado de direito democrático ${ }^{5}$ e da ligação deste direito com a liberdade de opinião, do livre desenvolvimento da personalidade garantido no art. $26^{\circ}$, $\mathrm{n}^{\circ} 1$, da CRP. Saliente-se que, tal como é hoje reconhecido, o livre desenvolvimento da personalidade tem de contemplar o desenvolvimento em grupo e a proibição de isolamento do cidadão.

É questionável se já se integra no conceito constitucional de reunião (art. $45^{\circ}$ da CRP) o "encontro" de um grupo de jovens num determinado local para tocar ou ensaiar música, ou simplesmente para conviver. Isto é válido, em geral, para os encontros culturais e desportivos de participação activa, pois neles parece ser evidente a já referida ligação interna. Mas esta já não existe quando as pessoas se mantêm numa atitude passiva, como meras espectadoras ou consumidoras, por exemplo os que assistem a um espetáculo de futebol ou a um filme. Numa primeira fase, prevaleceu um entendimento de que a reunião deveria ter um objeto amplo, abarcando os fins de convívio ou de caráter cultural. No entanto, mais recentemente vem-se impondo um entendimento bem mais restrito, que limita o objeto das reuniões e manifestações a fins de participação na formação da opinião pública.

Outra questão que se suscita tradicionalmente a propósito do direito de reunião tem a ver com o número mínimo de pessoas indispensável para se poder falar em reunião. No caso português, nem a Constituição, nem a lei, responde diretamente a esta questão. A Constituição fala apenas em "se reunir" (art. $45^{\circ}, n^{\circ} 1$ ). Desta formulação resulta, em rigor, que já pode haver reunião com apenas duas pessoas. A interpretação ampla do art. $45^{\circ}$ da CRP aponta para este entendimento, não se verificando fundamentos consistentes no nosso ordenamento jurídico para outra solução.

\section{CARÁCTER PACÍ́FICO E SEM ARMAS}

Quanto ao carácter pacífico, a Constituição estabelece como condição da proteção da reunião (e manifestação) o decurso pacífico e sem armas. Assim, o cidadão apenas tem o direito fundamental de reunião (e de manifestação) na condição de o exercer de forma pacífica e sem armas. A razão desta exigência prende-se com a necessidade, não só de garantir a ordem e a segurança públicas, mas também com a necessidade de assegurar aos demais participantes na reunião ou manifestação condições para que possam exercer o seu direito de reunião (e de manifestação) em condições de plena liberdade e segurança. Suscita-se, pois, a questão de saber o que se

\footnotetext{
${ }^{5} \mathrm{O}$ art. $1^{\circ}$ da CRP também faja em "sociedade livre" e o art. $2^{\circ}$ fala em "pluralismo de expressão" e em "democracia participativa".

${ }^{6}$ Cfr., por todos, Herzog, $M D$, art. $8^{\circ}$, n.m. 13.
} 
deve entender por carácter pacífico e sem armas, uma vez que a lei não clarifica esta expressão.

O carácter pacífico equivale ao estado de tranquilidade ou de ausência de desordem e de perturbação, em termos que não ponham em causa a ordem e a segurança públicas e que garantam aos demais participantes e ao público em geral condições de exercício em liberdade dos seus direitos. Assim, o carácter pacífico não implica a ausência de pequenas perturbações que possam ser consideradas aceitáveis, toleráveis ou mesmo "naturais" nos ajuntamentos de (muitas) pessoas.

Por outro lado, suscita-se a questão de saber o que devemos entender por "arma", uma vez que o direito de reunião (e de manifestação) tem necessariamente de ser exercido "sem armas". A lei $n^{\circ} 5 / 2006$, de 23 de fevereiro, que aprovou o novo regime jurídico das armas e suas munições, não adopta um conceito geral de arma, mas define (no seu art. $2^{\circ}, n^{\circ} 1$ ) múltiplos tipos de $\operatorname{arma}^{7}$. Para efeitos da proibição do art. $45^{\circ}$ da CRP, o conceito de "arma" deve ser entendido numa acepção ampla, no sentido técnico constante do referido art. $2^{\circ}$ da lei $n^{\circ} 5 / 2006$ (carabinas, espingardas, estiletes, estrelas de lançar, facas de arremesso, facas de borboleta, pistolas, pistolas-metralhadora, etc.), e em geral de qualquer objecto que possa ser utilizado como arma contra pessoas ou coisas, tais como tacos de baseball, correntes de ferro, barras de aço, quando sejam transportados com o fim de serem utilizados como arma. Porém, não integram o conceito de arma previsto no art. $45^{\circ}$ da CRP os objectos de mera protecção contra "perigos" espectáveis, tais como máscaras antigás, óculos de proteção, camisolas almofadadas, capacetes, etc., objectos que são muitas vezes designados de "armas passivas".

O carácter pacífico a que alude o art. $45^{\circ}$ da CRP não é fácil de definir, embora se deva aceitar como regra de orientação geral o decurso que não chega a pôr em causa ou a quebrar a ordem e a segurança públicas, ou seja, que não constitui ainda uma perturbação da ordem e segurança públicas. O carácter pacífico tem como pólo oposto o carácter violento ou insurreccional. É certo que, em geral, toda a violação da lei e do direito

\footnotetext{
${ }^{7}$ São eles, por ordem alfabética: a) «aerossol de defesa»; b) «arco»; c) «arma de acção dupla»; d) «arma de acção simples»; e) «arma de alarme»; f) «arma de ar comprimido»; g) «arma de ar comprimido desportiva»; h) «arma de ar comprimido de recreio»; i) «arma automática»; j) «arma biológica»; l) «arma branca»; m) «arma de carregamento pela boca»; n) «arma eléctrica»; o) «arma de fogo»; p) «arma de fogo curta»; q) «arma de fogo inutilizada»; r) «arma de fogo longa»; s) «arma de fogo modificada»; t) «arma de fogo transformada»; $u$ ) «arma lançadora de gases»; v) «arma lança-cabos»; x) «arma química»; z) «arma radioactiva ou susceptível de explosão nuclear»; aa) «arma de repetição»; ab) «arma semiautomática»; ac) «arma de sinalização»; ad) «arma de softair»; ae) «arma submarina»; af) «arma de tiro a tiro ou de tiro simples»; ag) «arma veterinária»; ah) «bastão eléctrico»; ai) «besta»; aj) «boxer»; al) «carabina»; am) «espingarda»; an) «estilete»; ao) «estrela de lançar»; ap) «faca de arremesso»; aq) «faca de borboleta»; ar) «faca de abertura automática ou faca de ponta e mola»; as) «pistola»; at) «pistolametralhadora»; au) «réplica de arma de fogo»; av) «reprodução de arma de fogo»; ax) «revólver».
} 
já representa uma perturbação da ordem e segurança públicas e, assim, em termos gerais, a perturbação do carácter pacífico de uma reunião (ou manifestação). Porém, a decisão a ser tomada in loco pelas autoridades policiais sobre a quebra do carácter pacífico não pode deixar de atender ao elevado significado do direito de reunião para o Estado de direito e para os participantes pacíficos, que não devem ser impedidos do exercício do seu direito fundamental sem uma razão suficientemente forte. Neste sentido, só uma situação de alguma gravidade que represente um elevado perigo para bens jurídicos fundamentais pode constituir uma quebra do carácter pacífico e, assim, servir de fundamento de dissolução (perda do direito de reunião). Conclui-se, pois, que, para efeitos de dissolução de uma reunião, nem toda a violação do direito, nem mesmo do direito penal, constitui automaticamente uma quebra do carácter pacífico. O carácter pacífico deve ser apreciado face às circunstâncias do caso concreto e sempre tendo como linha de orientação a impossibilidade de assegurar em geral aos que se reúnem (ou manifestam) pacificamente condições de segurança para o exercício do seu direito fundamental.

Foi referido que o carácter pacífico não se verifica quando há violência ou insurreição em termos de não permitir às autoridades continuarem a assegurar o livre exercício dos direitos daqueles que se comportam de forma pacífica. A violência caracteriza-se pelo emprego de força física, de forma agressiva e com gravidade, contra pessoas ou coisas (por exemplo montras ou automóveis estacionados no local) ${ }^{8}$. Diferentemente, o carácter insurreccional resulta de actos de subversão, quer como objectivo global da reunião (ou manifestação), quer como objectivo de parte dos participantes em termos de não ser possível assegurar aos que se comportam pacificamente a continuação do exercício do seu direito. Frequentemente, a violência é exercida contra os agentes de autoridade quando procuram assegurar o respeito pela lei. A questão da quebra do carácter pacífico de uma reunião (ou manifestação) coloca-se de forma mais problemática no caso de não serem praticados actos físicos de violência, mas de a reunião (ou manifestação) se orientar para fins subversivos ou de propagação de ideais subversivos. Uma resposta neste domínio tem de ser encontrada em harmonia com a liberdade de expressão e de opinião (art. $37^{\circ}$ da CRP).

Uma questão que se tem colocado de forma especial em sede de carácter pacífico ou violento de uma reunião ou manifestação tem a ver com o chamado bloqueio de manifestantes sentados. Ainda que se trate de uma questão controversa na doutrina e na jurisprudência, a solução mais sustentável à partida face à Constituição é a de considerar que o simples reunir-se sentando-se de forma a provocar um efeito bloqueio (por exemplo

\footnotetext{
${ }^{8}$ O Tribunal Constitucional Federal alemão considera (BVerfG, NJW 2006, 136) que, face ao agente de intervenção que actua nos termos da lei, já é suficiente uma gravidade de pequena dimensão para que haja violência.
} 
num acesso a uma instalação pública) não constitui ainda violência de forma a quebrar o carácter pacífico da reunião (ou manifestação). O mesmo carácter pacífico continua a verificar-se no caso de os que se reúnem (ou manifestam) se ligarem com correntes entre si.

Outra questão que se tem colocado consiste em saber se constitui acto de violência para efeitos de uma eventual quebra do carácter pacífico de uma reunião ou manifestação o arremesso de certos objectos moles que não causam normalmente um dano físico, como por exemplo, ovos ou tomates. A resposta a esta questão não pode ser dada globalmente, mas também aqui se deve ter em consideração as circunstâncias do caso concreto, como por exemplo contra quem é feito o arremesso, se ele é feito apenas com o intuito de chamar a atenção para um problema ou com o intuito de lançar o atingido no ridículo ou ainda se, embora normalmente o arremesso daquele tipo de objecto não provoque dano, o tenha provocado na realidade.

Diferente do carácter (pacífico ou não) global da reunião é o comportamento de pessoas em concreto que se reúnem (ou manifestam). Neste caso, a resposta sobre a quebra do carácter pacífico está ligada ao apoio a estas condutas violentas e perturbadoras por parte do grupo. A conduta violenta de pessoas em concreto quando não seja apoiada pelo grupo não põe em causa o carácter pacífico da reunião (ou manifestação). Neste caso, o perturbador deve ser, pura e simplesmente, intimado a pôr termo à violência, sob pena de ser retirado do grupo e, assim, privado do seu direito. Mas a questão é bem mais difícil de ultrapassar quando em vez de uma ou duas pessoas é um subgrupo de uma certa dimensão e não é claro o seu apoio ou cobertura pelos restantes. Por outro lado, a situação de apoio ou não apoio pelos restantes pode não só mudar, como aquele que começou por ser um acto de violência isolado pode rapidamente alastrar em cadeia.

Finalmente, para que o carácter pacífico de uma reunião (ou manifestação) seja quebrado não deve ser sempre exigido a prática consumada de violência. Já não há carácter pacífico quando estamos perante uma grave ameaça de violência ou insurreição, em termos de ser iminente a sua concretização. Situações deste tipo podem ocorrer, desde logo no caso de apelo a ações de clara ilicitude grave, como por exemplo o corte de uma estrada, o bloqueio a uma emissão radio-televisiva ou exercício do direito de reunião de forma a impedir o exercício do mesmo direito por parte de outros.

\section{REUNIÕES PÚBLICAS E NÃO PÚBLICAS}

Outra importante questão consiste na delimitação que deve ser feita entre reuniões públicas e não públicas, consoante haja ou não a possibilidade de acesso a ela de qualquer pessoa'. Na verdade, a garantia constitucional

\footnotetext{
${ }^{9}$ Como se referio noutro local, "o carácter público da reunião deve ser determinado a partir do direito de acesso à reunião e não a partir do facto de a realização da reunião ser perceptível pelo público em geral" (Reuniões e Manifestações no Estado de Direito. Saraiva, p. 44).
} 
da liberdade de reunião e de manifestação de que aqui se trata diz respeito apenas às reuniões e manifestações públicas ou abertas ao público. As reuniões e manifestações públicas ou abertas ao público são antes de mais aquelas cujo acesso é aberto a qualquer pessoa, mas também aquelas que por natureza são reservadas a determinados grupos de pessoas ${ }^{10}$ (p. ex. grupos profissionais, como médicos, estivadores). Para o caráter público ou não público da reunião é determinante a existência de um convite individual ou, inversamente, de apelo dirigido ao público em geral de um organizador. O carácter público de uma reunião não depende de ter ou não havisto um controlo à entrada para o local de reunião (por exemplo, de uma secção local de um partido político), o qual se pode dever a razões de segurança. Importante é que "o carácter público de uma reunião deve ser analisado também conjuntamente com a possibilidade que o organizador ou dirigente tem de, eventualmente, no caso concreto, excluir determinadas pessoas ou grupos de pessoas, por exemplo, através da emissão de convites"11.

\section{ALCANCE DA GARANTIA DO DIREITO DE REUNIÃO}

Importante é também o alcance da garantia da liberdade de reunião e de manifestação em concreto. A garantia constitucional do direito de reunião (e de manifestação) (art. $45^{\circ}$ da CRP) abarca a organização, a preparação (envio de convites, publicidade), a escolha do lugar e da hora do evento, o acesso ao local, o abandono dele, a direcção interna da reunião, a participação na reunião (incluindo daqueles que discordam do objeto da reunião, do seu fim e do andamento dos trabalhos, os quais podem revelar essa discordância - os chamados críticos. Porém, não pode invocar o direito de reunião aquele que se dirige para a reunião com o intuito de a boicotar ou que, durante o seu decurso pacífico, pratica atos com vista ao seu boicote (por exemplo, apupando constantemente). O boicote ao andamento dos trabalhos e à reunião em geral, diferentemente da simples discordância, não é uma forma de participação. Finalmente, no domínio da perspectiva individual do cidadão, o art. $45^{\circ}$ da CRP garante a chamada liberdade de não organizar ou participar em reuniões (ou manifestações), do que resulta que ninguém poder ser obrigado a organizar ou a participar em reuniões (ou manifestações). Por fim, o carácter público assenta também no fim que obrigatoriamente deve animar as reuniões. O objecto da reunião pode também ser um auxiliar (não excludente) precioso para a sua caracterização como pública. Os "objectos públicos" são aqueles que respeitam ao interesse geral (de âmbito local, regional, nacional ou internacional) e têm configuração política, podendo versar os mais diversos domínios da vida social. A eventual emissão de bilhetes (com ou sem pagamento) de entrada não exclui, por si só, o carácter público ${ }^{12}$.

\footnotetext{
${ }^{10}$ SOUSA, António Francisco de. Reuniões e Manifestações no Estado de Direito. Saraiva, p. 44. Um congresso partidário deve, em regra, ser considerado reunião não pública, porque nele apenas participam determinados delegados e convidados especiais.

${ }_{11}^{11}$ SOUSA, António Francisco de. Reuniões e Manifestações no Estado de Direito. Saraiva, p. 45.

${ }^{12}$ SOUSA, António Francisco de. Reuniões e Manifestações no Estado de Direito. Saraiva, p. 46.
} 


\section{INGERÊNCIAS NO DIREITO DE REUNIÃO}

Outro aspeto que suscita problemas importantes na abordagem do direito de reunião e de manifestação consiste na questão da ingerência. Constituem ingerência no direito de reunião as exigências que a lei ordinária faz para o seu exercício. Estão em causa, por exemplo, a obrigação de "avisar" as autoridades competentes ou, em certos casos, de obter junto delas uma licença prévia ao exercício do direito de reunião. Por outro lado, também são ingerências, na perspectiva da autoridade, as proibições e dissoluções de reuniões, as imposições de ónus, as exclusões de participantes em concreto, os impedimentos e limitações por ocasião da chegada e da partida dos que se reúnem (ou manifestam).

Relativamente às medidas adoptadas pelas forças policiais por ocasião do seu controlo da reunião (ou manifestação), o seu carácter de ingerência é mais controverso. Estão em causa medidas como "observações" e "gravações" (de imagem e som ou fotográficas). Se estas medidas se destinarem a provocar e provocarem um efeito de intimidação nos que se reúnem (ou manifestam), será de aceitar o seu carácter de ingerência. Isto porque, com a garantia do direito de reunião é simultaneamente garantida a livre decisão pessoal de se reunir (ou manifestar). Ora, se no caso concreto as medidas de controlo das forças policiais forem de natureza a provocar um efeito de intimidação naquele que pretende exercer ou já está a exercer o seu direito de reunião (ou manifestação), de modo a levá-lo a preferir não se reunir ou não continuar na reunião, haverá uma ingerência no seu direito fundamental de reunião (ou manifestação). Em geral, será de reconhecer às forças policiais um poder para adoptar este tipo de medidas dentro dos limites de normalidade, independentemente do efeito que isso provoca nos que se pretendem reunir ou estão reunidos. Mas se as medidas de controlo das forças policiais forem claramente excessivas tendo em vista as circunstâncias do caso concreto e os bens a salvaguardar e, simultaneamente, provocarem um efeito de intimidação, já constituirão ingerência no direito fundamental de reunião (ou de manifestação). Também já haverá ingerência no caso de observações e gravações da reunião em si considerada e/ou de participantes nessa qualidade. Porém, tratando-se da observação de um suspeito ou de grupos de suspeitos que já está sob observação policial nos termos da lei, não haverá ingerência apenas porque a observação é feita na preparação ou no decurso de uma reunião (ou manifestação). De igual modo, constitui ingerência no direito de reunião o "acompanhamento intenso" das forças policiais fortemente equipadas circundando uma reunião ou de ambos os lados de uma manifestação. Neste caso, para além de um eventual efeito de intimidação, verifica-se um "corte" ou uma "barreira" de difícil transposição entre os que se reúnem (ou manifestam) e o público em geral, de modo a dificultar a livre circulação e transmissão de ideias. 


\section{LIMITAÇÕES À LIBERDADE DE REUNIÃO E DE MANIFESTAÇÃO}

\subsection{A Reserva de Lei no Direito de Reunião}

As restrições constantes da "Lei das Reuniões" (por exemplo as restrições relativas às zonas interditas a reuniões, aos domingos e feriados) aplicam-se apenas às reuniões públicas, isto é, acessíveis a qualquer pessoa. Mas as leis das forças de segurança (especialmente da PSP e da GNR) e as leis de ordenação (ou de polícia administrativa) prevêem outras restrições, o mesmo acontecendo com as leis de circulação em estradas e caminhos e o código de estrada. Neste domínio, importa ter presente que o exercício do direito de reunião (e de manifestação) é uma das formas possíveis (legítimas) de uso colectivo da via pública, não sendo menos legítimo que a circulação rodoviária.

A "Lei das Reuniões" é uma lei especial face à legislação policial e ordenacional geral e ao código de estrada. Por isso, aplica-se com prioridade face a estas leis (princípio segundo o qual a lei especial precede e bloqueia a aplicação da lei geral). Mas a lei das reuniões, enquanto lei especial, apenas se aplica até onde ela alcança. Assim, na falta de regulação expressa da Lei das Reuniões, as autoridades competentes e as forças policiais devem apoiar as suas medidas nas leis policiais gerais (especialmente leis orgânicas da PSP e da GNR, no que regulam em matéria de actuação policial). Será o caso, por exemplo, de medidas policiais que podem ser necessárias contra manifestantes que estão a chegar e que a lei das reuniões não prevê (medidas preparatórias). Também deve ser aplicado o princípio da precedência das "medidas menos ablativas", que não está previsto na lei das reuniões, mas que faz parte das regras de actuação policial em geral. Assim, as forças policiais devem, na sua actuação ligada a reuniões (e manifestações) públicas, dar preferência a uma ingerência menos ablativa quando esta se revele igualmente adequada a atingir o fim legal em vista.

\subsection{Proibição de Participação em Reunião}

Outra importante questão que se suscita no domínio do direito de reunião e de manifestação consiste em saber até que ponto este direito pode ser negado aos militares e aos agentes policiais. A lei militar e a legislação das forças policiais proíbe que militares e agentes policiais se manifestem fardados ou participem fardados em reuniões de carácter político em espaços fechados ou abertos.

\subsection{Direito Constitucional Colidente}

Não menos importante é a questão da colisão do direito de reunião e de manifestação com outros direitos fundamentais, que acontece frequentemente na prática. Se, por exemplo, a polícia toma conhecimento de que, possivelmente, uma bomba irá explodir numa reunião pública em espaço fechado (ou aberto), poderá dissolver imediatamente a reunião. Neste caso, verifica-se uma situação de "perigo directo para a vida e para a saúde dos participantes". A salvaguarda da vida e da saúde dos participantes colide com a garantia do direito de reunião (ou de manifestação). 


\section{PROIBIÇÃO DE EXIGÊNCIAS INJUSTIFICADAS}

Outra importante questão consiste na proibição de exigências injustificadas. Por outro lado, uma eventual obrigação de nomeação de um diretor para a reunião ou manifestação seria de constitucionalidade duvidosa, sobretudo em certos casos. Na verdade, enquanto uma tal obrigação seria perfeitamente aceitável no caso de reuniões de maior dimensão - devido ao facto de tais reuniões necessitarem, para a sua devida organização, de um diretor, já que a nomeação de um director serve à concretização do direito de reunião -, uma tal exigência não é sustentável no caso de reuniões de pequena dimensão, sendo neste caso inconstitucional.

\section{PROIBIÇÃO DE SUJEIÇÃO A AUTORIZAÇÃO}

Mais pacífica é a proibição de obrigação de autorização. $O$ art. $45^{\circ}, n^{\circ} 1$, da CRP exclui expressamente a possibilidade de subordinação do direito de reunião a uma autorização prévia. Este é, pois, um limite de limites. Ainda que não previstas expressamente, estão nesta linha também a proibição de censura e a proibição absoluta de obrigação de comunicação prévia. A Lei das Reuniões não pode transformar a comunicação às autoridades numa obrigação absoluta, nem pode punir o incumprimento do dever de comunicação. A lei das reuniões pode, no entanto, estabelecer um dever geral de comunicação prévia às autoridades competentes de forma a permitir que elas tomem em tempo útil conhecimento do projecto de reunião e possam adoptar as medidas necessárias para garantir um decurso pacífico e em segurança para os que se reúnem (ou manifestam), para a fluidez do trânsito e, em geral, para a segurança e a ordem públicas. O incumprimento do dever de comunicação prévia às autoridades competentes não pode dar origem, de forma automática, à dissolução da reunião. A falta de comunicação prévia às autoridades gera apenas um aumento do risco de a reunião (ou manifestação) ter de ser dissolvida ou da necessidade de imposição de alguns ónus (p. ex. desvio do circuito no caso de desfiles), como exigência para se evitarem perigos para a ordem e segurança públicas, que bem poderiam ter sido evitados se tivesse havido aviso prévio. O aviso prévio não faz sentido na reunião espontânea ( $p$. ex. de pessoas que se concentram espontaneamente, evoluindo a concentração para uma reunião ou manifestação) e pode estar excluído ou ser mais compreensível na reunião urgente (no caso de organização prévia, mas sem tempo para o aviso prévio que é geralmente de dois dias úteis).

\section{CONCLUSÕES}

Os direitos de reunião e de manifestação suscitam muitas questões jurídicas importantes e de difícil resposta ${ }^{13}$. Por se tratar de uma figura central do Estado de direito democrático, o direito de reunião e de manifestação deve merecer a maior atenção por parte dos estudiosos e práticos do direito,

\footnotetext{
${ }^{13}$ Para maiores desenvolvimentos, cf. SOUSA, António Francisco de. Reuniões e Manifestações no Estado de Direito. 2. ed., São Paulo: Saraiva, 2011.
} 
para que os direitos e liberdades subjacentes sejam devidamente conciliados com outros direitos e liberdades de cada um, de grupos sociais e da sociedade em geral. Por se estar no domínio dos direitos e liberdades fundamentais, a atuação das forças policiais encarregadas de salvaguardar a ordem e a segurança públicas deve também ser clara e transparente, para que as restrições sejam legais e reduzidas ao mínimo indispensável.

\section{BIBLIOGRAFIA}

BÄUMLER, Helmut. Versammlungsfreiheit und Verfassungsschutz. JuristenZeitung. V. 41, n 10, 1986.

CORREIA, J. M. Sérvulo. O Direito de Manifestação - Âmbito de Protecção e Restrições. Coimbra: Almedina, 2006.

DIETEL, Alfred; GINTZEL, Kurt; KNIESEL, Michael. Demonstrations- und Versammlungsfreiheit - Kommentar zum Gesetz über Versammlungen und Aufzüge. 14. ed., Colônia: Carl Heymanns Verlag, 2005.

ENDERS, Christoph. Der Schutz der Versammlungsfreiheit. Jura. 2003.

GRÖPL, Christoph. Grundstrukturen des Versammlungsrechts. Jura. 2002.

GUSY, Christoph. Rechtsextreme Versammlungen als Herausforderung an die Rechtspolitik. JuristenZeitung. № 2. 2002.

HOFFMANN-RIEM, Wolfgang. Neuere Rechtsprechung des BVerfG zur Versammlungsfreiheit. NVwZ (Neue Zeitschrift für Verwaltungsrecht). 2002.

LAUBINGER, Hans-Werner; REPKEWITZ, Ulrich. Die Versammlung in der verfassungsund verwaltungsgerichtlichen Rspr. VerwArch (Verwaltungsarchiv). № 92. 2001; no 93. 2002.

SOUSA, António Francisco de. Direito de Reunião e de Manifestação. Quid Juris: Lisboa, 2009.

, A Polícia no Estado de Direito. São Paulo: Editora Saraiva, Brasil, 2009.

Para uma "Lei das Reuniões e Manifestações em Lugares Públicos ou Abertos ao Público". in: Volume Comemorativo dos 20 Anos do Instituto Superior de Ciências Policiais e Segurança Interna. Lisboa, 2005. p. 573-598.

, in: VALENTE, Manuel M. G. (coord.). Reuniões e Manifestações - Actuação Policial. Centro de Investigação do ISCPSI. Coimbra: Almedina 2009.

Intervenção Policial, Liberdade Artística e Violência Doméstica. Politeia, $\overline{R e v i s t a}$ do Instituto Superior de Ciências Policiais e Segurança Interna. Ano I, $\mathrm{n}^{\circ} 2$, jul./dez. 2004. Almedina: Coimbra.

, Direito de Reunião e de Manifestação no Estado de Direito: fundamento, significado e carácter pacífico. in: Actas do Colóquio do Porto. 2006.

A Polícia como garante da Ordem e Segurança Públicas. (comunicação apresentada no colóquio "O Estado da Polícia", realizado na Faculdade de Direito da Universidade do Porto, a 23 de Abril, de 2002). RMP. no 90, p. 79-89. 2002.

- Prevenção do Perigo como Função das Forças de Segurança e das Autoridades de Polícia Administrativa. Polícia Portuguesa. nº 105. 1997.

Actuação Policial e Princípio da Proporcionalidade. Polícia Portuguesa. n 113. 1998. 